\title{
Perancangan Siklus Rankine Organik Untuk Pemanfaatan Gas Buang Pada PLTU di Indonesia
}

\author{
Mohammad Azis M \\ Jurusan Teknik Mesin, Fakultas Teknik Industri, ITENAS, Bandung \\ Email : m.azis.mahardika@gmail.com
}

\begin{abstract}
ABSTRAK
Energi merupakan kebutuhan pada kehidupan manusia. Sumber energi fossil yang digunakan untuk memenuhi kebutuhan energi semakin lama semakin menipis. Sehingga diperlukan sumber energi alternatif atau peningkatan efisiensi dalam pemanfaatan energi. Panas buang merupakan salah satu sumber energi alternatif. Pemanfaatan panas buang salah satunya adalah dengan menggunakan siklus rankine organik. PLTU memiliki panas buang yang berpotensi untuk dimanfaatkan. Temperatur gas buang pada PLTU yang rata-rata sebesar $150{ }^{\circ} \mathrm{C}$. Proses perancangan dilakukan untuk memanfaatkan panas buang hasil pembakaran. Hasil perancangan sistem siklus rankine organik mampu menghasilkan daya sebesar $6053 \mathrm{~kW}$ (R142b), $5705 \mathrm{~kW}$ (R123), dan 5502 (Isopentane) serta efisiensi sebesar 18.54\%, 18.51\%, dan 17.85\% untuk fluida kerja R142b, R123, dan Isopentane.
\end{abstract}

Kata kunci:siklus rankine organik, gas buang, panas sisa

\begin{abstract}
Energy is needeed for human life. Fossil energy which used to fulfill our needs is diminished. So, alternative energy source is used. Waste heat are one of a kind energy alternative source. Organic rankine cycle can be used to utilitze waste heat. Coal power plant which have flue gas to utilized. Average flue gas temperature in coal power plant are $150^{\circ} \mathrm{C}$. Design process to utilize waste heat has been conducted. The power produced in the system are $6053 \mathrm{~kW}, 5705 \mathrm{~kW}$, and $5502 \mathrm{kWalso}$ the efficiency are $18.54 \%, 18,51 \%$, and $17,85 \%$ for working fluid R142b, R123, and Isopentane respectively.
\end{abstract}

Keyword: organic rankine cycle, waste heat, flue gas 


\section{PENDAHULUAN}

Energi merupakan kebutuhan pada kehidupan manusia. Semakin bertambah jumlah penduduk, maka kebutuhan energi juga meningkat. Sumber energi fossil yang digunakan untuk memenuhi kebutuhan energi semakin lama semakin menipis. Sehingga diperlukan sumber energi alternatif atau peningkatan efisiensi dalam pemanfaatan energi. Panas buang merupakan salah satu sumber energi alternatif. Panas buang adalah panas yang dibangkitkan dari pembakaran bahan bakar atau reaksi kimia yang kemudian dibuang ke lingkungan walaupun masih dapat digunakan [1]. Pemanfaatan panas buang bermanfaat untuk mengurangi polusi, konsumsi energi untuk peralatan bantu (kipas, pompa, dll).

Indonesia memiliki mayoritas pembangkit listrik tenaga uap [2]. PLTU memiliki panas buang yang berpotensi untuk dimanfaatkan. Temperatur gas buang pada PLTU yang rata-rata sebesar $150 \mathrm{C}$ mampu dimanfaatkan [3]. Pemanfaatan panas buang salah satunya adalah dengan menggunakan siklus rankine organik.

Saat ini, teknologi ORC ( Organic Rankine Cycle) berkembang semakin pesat, sehingga limbah limbah panas yang awalnya dibuang begitu saja, sekarang menjadi potensi untuk membangkitkan listrik dengan ORC. Prinsip kerja ORC sama dengan RC (Rankine Cycle) hanya saja berbeda pada fluida kerjanya. ORC dapat memanfaatkan sumber panas dengan temperatur sekitar $80^{\circ} \mathrm{C}$, dikarenakan titik didih fluida organik yang rendah. Kelebihan dari siklus ORC adalah mampu bekerja pada temperatur rendah. Pemanfaatan limbah panas ini mampu menghasilkan energi listrik tambahan yang dapat meningkatkan efisiensi, dan meminimalisir panas yang terbuang ke lingkungan serta penghematan bahan bakar[4].

Dengan memanfaatkan gas buang hasil pembakaran pada PLTU, diharapkan hasil perancangan siklus ORC dari paper ini dapat meningkatkan efisiensi dan menghemat bahan bakar dari PLTU. Selain itu, pemilihan fluida kerja organik juga mempengaruhi efisiensi siklus organik, pada paper ini juga dibahas pengaruh dari pemilihan fluida kerja organik terhadap performa siklus rankine organik.

\section{METODOLOGI}

\subsection{Metodologi Penelitian}

Proses perancangan dimulai dari menentukan parameter desain dari data-data yang diperoleh dari literatur dan lapangan. Selanjutnya sistem dirancang sesuai dengan parameter yang diinginkan. Perangkat lunak REFPROP digunakan untuk memperoleh sifat-sifat termodinamika dari fluida kerja organik. Pada proses ini fluida organik yang digunakan hanya 3 macam yaitu R142b, R123, dan Iso-pentane. Diagram alir proses perancangan dapat dilihat pada gambar 1 


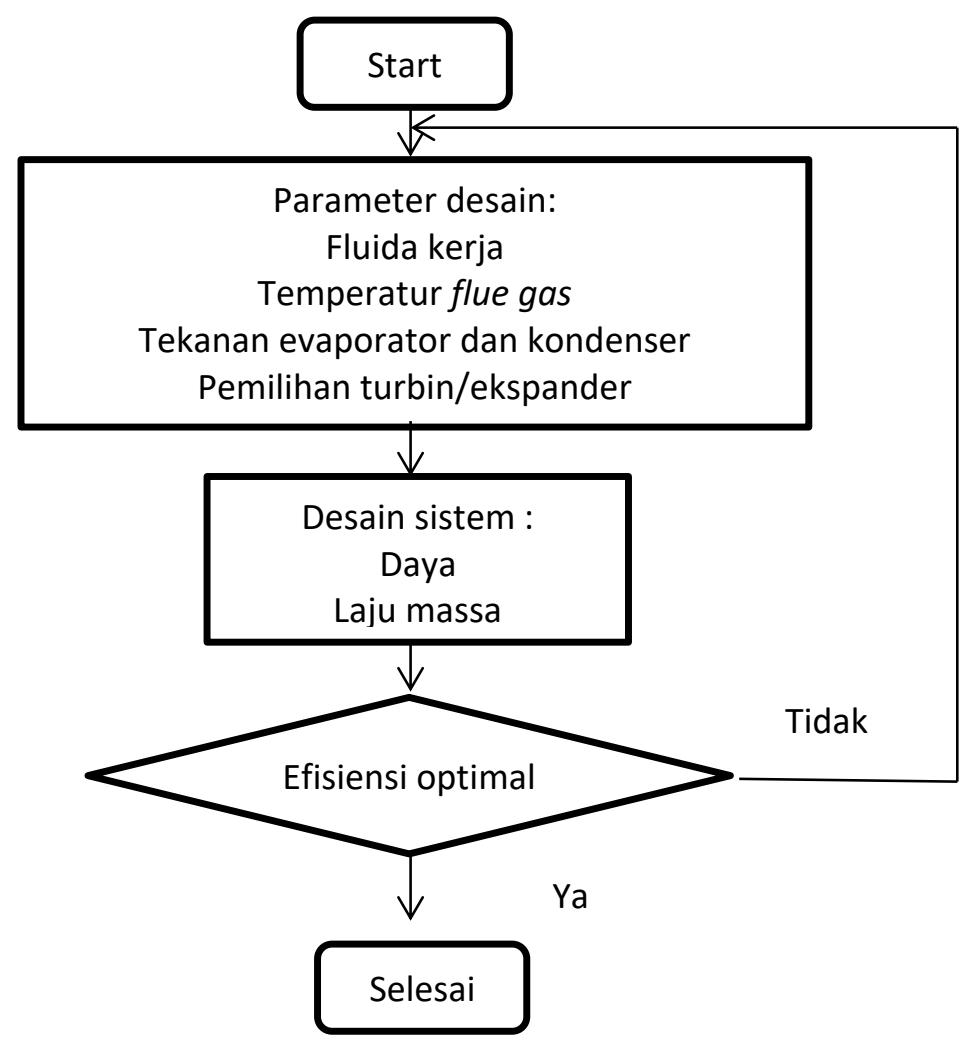

Gambar 1. Flow chart desain siklus rankine organik

\subsection{Deskripsi Siklus Rankine Organik}

Perancangan sistem akan dijelaskan secara berurutan. Secara keseluruhan sistem memiliki skema sebagai berikut

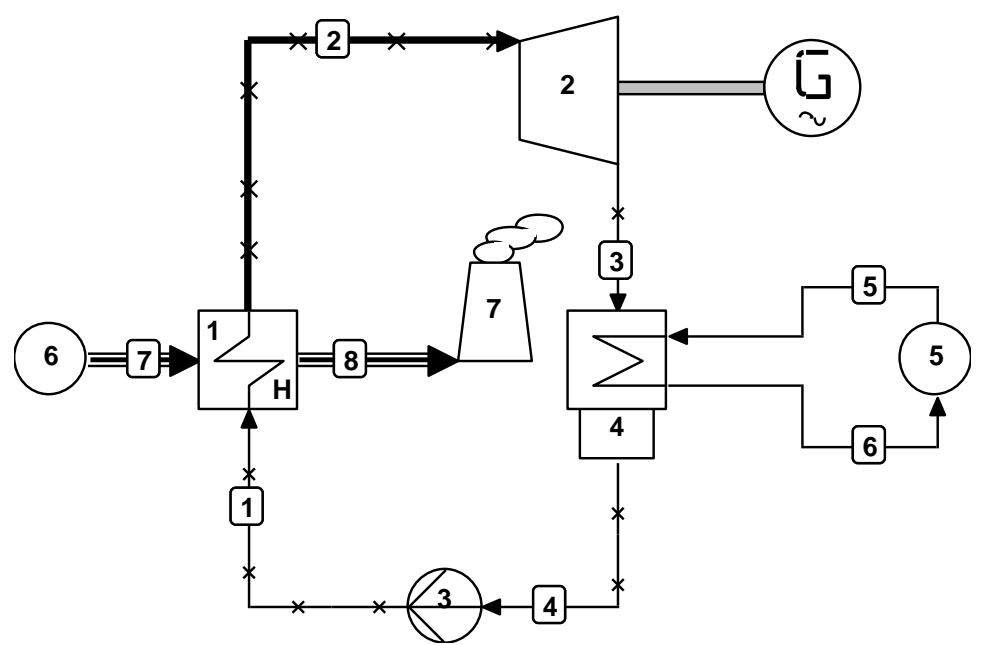

Gambar 2. Sistem siklus organik

Gas buang hasil pembakaran dimanfaatkan untuk memanaskan udara. Proses ini terjadi pada komponen air preheater. Setelah proses ini gas buang sudah tidak dimanfaatkan lagi panasnya. Setelah proses tersebut gas buang akan dialirakan ke lingkungan melalui stack. Gas buang pada bagian ini masih memiliki panas yang dapat dimanfatkan. Temperatur gas buang yang mencapai $120-150{ }^{\circ} \mathrm{C}$ pada proses gas buang masih memiliki potensi untuk pemanfaatan panas [5]. Salah satu cara pemanfaatanya adalah dengan menggunakan siklus rankine organik. Siklus rankine 
organik memanfaatkan panas dengan temperatur rendah, untuk menguapkan fluida kerja organik yang memiliki temperatur didih rendah. Dalam pemanfaatan fluida kerja organik, terdapat beberapa faktor yang harus diperhatikan seperti sumber panas, pengaruh terhadap lingkungan, dan sifat termodinamika.[6]. Pada desain siklus rankine organik ini digunakan 3 macam fluida organik dalam perancangan siklus rankine organik. Fluida kerja yang digunakan memiliki sifat yang berbeda-beda. Sifat dari fluida kerja ditunjukkan pada tabel 1.

Tabel 1. Sifat fluida kerja organik

\begin{tabular}{|l|l|l|l|l|l|l|}
\hline \multicolumn{1}{|c|}{ Fluida } & \multicolumn{1}{|c|}{ Formula } & $\begin{array}{c}\text { T kritik } \\
(\mathrm{K})\end{array}$ & $\begin{array}{c}\text { P kritik } \\
(\text { atm })\end{array}$ & ODP & GWP & Karakteristik \\
\hline \hline $\mathrm{R} 142 \mathrm{~b}$ & $\mathrm{C}_{2} \mathrm{ClF}_{2} \mathrm{H}_{3}$ & 410.26 & 40.59 & 0.07 & 2130 & Kering \\
\hline $\mathrm{R} 123$ & $\mathrm{CHCl}_{2} \mathrm{CF}_{3}$ & 456.83 & 36.61 & 0.06 & 77 & Isentropic \\
\hline Isopentane & $\left(\mathrm{CH}_{3}\right)_{2} \mathrm{CHCH}_{2} \mathrm{CH}_{3}$ & 460.35 & 33.78 & 0 & 4.6 & Kering \\
\hline
\end{tabular}

$\mathrm{R} 142 \mathrm{~b}$ dan isopentane memiliki karakteristirk kering, karakteristik ini menunjukkan hasil ekspansi dari fluida akan tetap berfasa kering (kurva memiliki kemiringan positif) sedangkan fluida R123 memiliki karakteristik isentropik (kurva memiliki kemiringan tidak terhingga). Contoh kurva dengan karakteristik basah, kering, dan isentropik ditunjukkan pada gambar 3
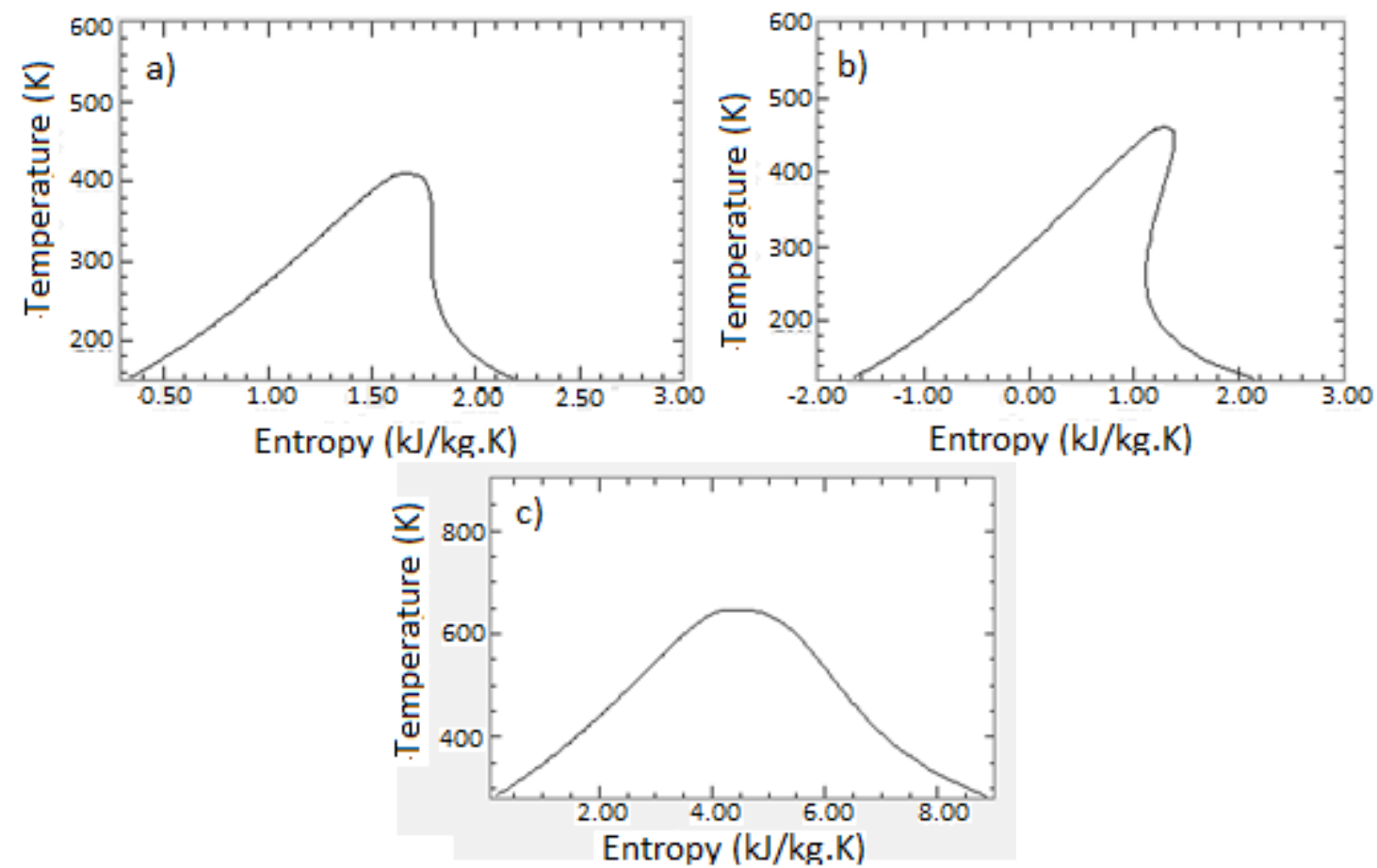

\section{Gambar 3. Karakteristik fluida kerja organik a) isentropik b) kering c) basah [7]}

Pada pemanfaatan panas buang PLTU, penurunan temperatur gas buang dibatasi sampai $100^{\circ} \mathrm{C}$. Hal ini bertjuan untuk menghindari kondensasi uap air dan sulfur yang terkandung pada gas buang. Fenomena ini dapat mengganggu kinerja komponen-komponen PLTU pada bagian gas treatment (FGD, stack, dll).

Diagram T-s siklus rankine organik ditunjukkan pada gambar 4. Tekanan evaporator merupakan parameter utama dari sistem. Tekanan evaporator ditentukan dari temperatur pinch dari gas buang dengan fluida kerja. Temperatur pinch dirancang sebesar $5{ }^{\circ} \mathrm{C}$. Temperatur pinch berpengaruh pada luas area evaporator, semakin kecil temperatur pinch maka luas area yang dibutuhkan dari penukar panas akan semakin besar. 


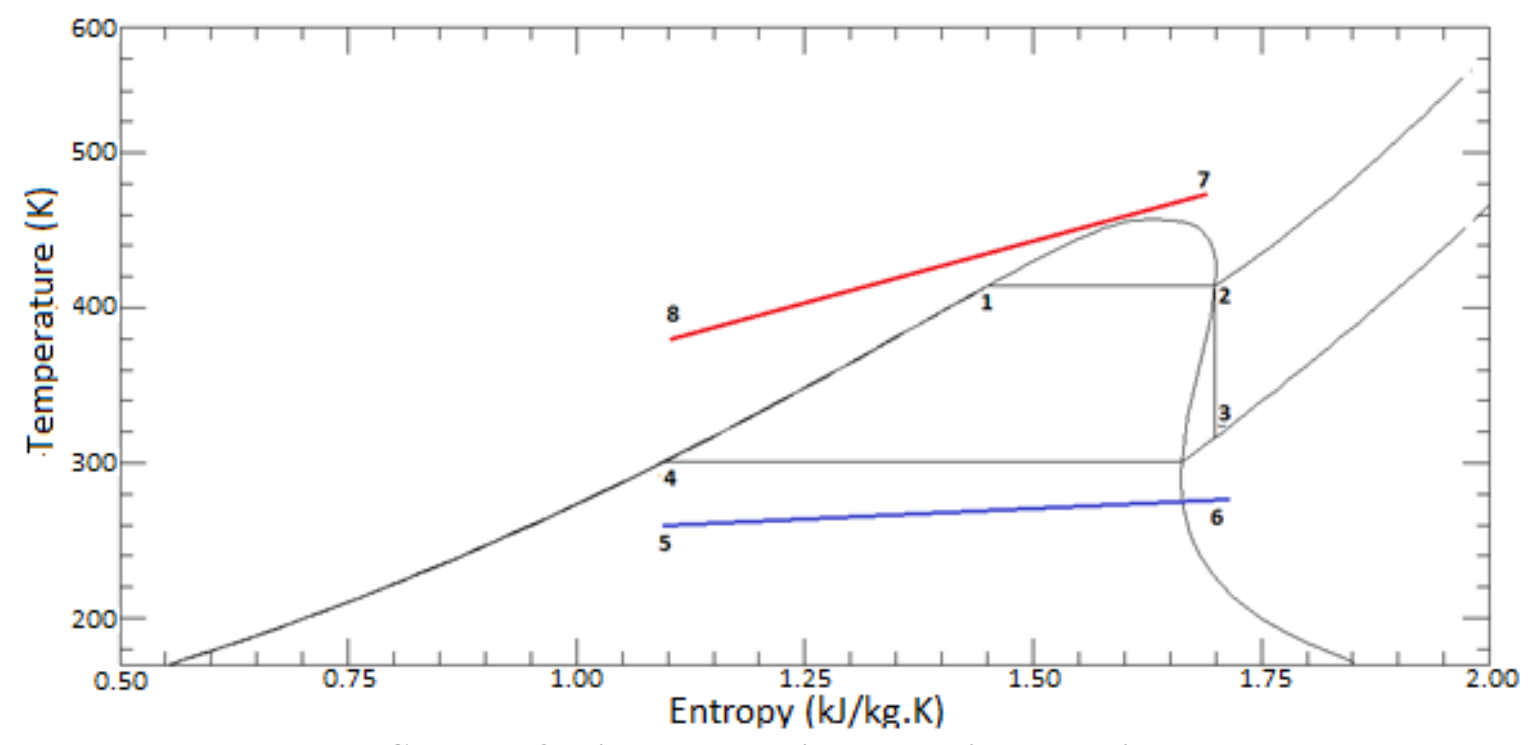

Gambar 4. Diagram T-s siklus rankine organik

\subsection{Analisis Sistem}

Untuk menganalisis sistem maka digunakan perhitungan kesetimbangan energi pada masingmasing komponen

- $\quad$ Pompa

$$
\begin{gathered}
\eta_{p}=\frac{h_{1 s}-h_{4}}{h_{1}-h_{4}} \\
W_{p}=\dot{m}_{f o}\left(h_{2}-h_{1}\right)
\end{gathered}
$$

- Turbin

$$
\begin{gathered}
\eta_{t}=\frac{h_{3 s}-h_{2}}{h_{3}-h_{2}} \\
W_{t}=\dot{m}_{f o}\left(h_{3}-h_{2}\right)
\end{gathered}
$$

- Evaporator

$$
\begin{gathered}
\dot{Q}_{f o, e v a}=\dot{m}_{f o}\left(h_{2}-h_{1}\right) \\
\dot{Q}_{f g, e v a}=\dot{m}_{f g}\left(h_{5}-h_{6}\right) \\
\dot{Q}_{f o, e v a}=\dot{Q}_{f g, e v a}
\end{gathered}
$$

Untuk menghitung enthalpy dari gas buang sama dengan enthalpy parsial dari masing masing komponen.[8]

$$
\begin{aligned}
h_{f g}=h_{f g}(T)+w \cdot h_{w}(T)= & \left(y_{o_{2}} h_{o_{2}}(T)+y_{c o_{2}} h_{c o_{2}}(T)+y_{n_{2}} h_{n_{2}}(T)\right)+w \cdot h_{w}(T) \\
& y_{o_{2}}+y_{c o_{2}}+y_{n_{2}}=1
\end{aligned}
$$

- $\quad$ Kondensor

$$
\begin{gathered}
\dot{Q}_{f o, \text { cond }}=\dot{m}_{f o}\left(h_{3}-h_{4}\right) \\
\dot{Q}_{w, \text { cond }}=\dot{m}_{w, \text { cond }} \\
\dot{Q}_{f o}=\dot{Q}_{f g}
\end{gathered}
$$

Optimasi dilakukan dengan memvariasikan tekanan evaporator sehingga didapatkan efisiensi yang optimal. Tabel 2 menunjukkan tingkat keadaan dan parameter perancangan siklus rankine organik. 
Tabel 2. Parameter perancangan sistem rankine organik

\begin{tabular}{|l|l|l|}
\hline \multicolumn{1}{|c|}{ Parameter } & \multicolumn{1}{c|}{ Nilai } & Satuan \\
\hline \hline Temperatur gas buang & 423 & $\mathrm{~K}$ \\
\hline Temperatur pinch & 5 & $\mathrm{~K}$ \\
\hline Tekanan evaporator & $0.8-2.8$ & $\mathrm{MPa}$ \\
\hline Temperatur air pendingin & 298 & $\mathrm{~K}$ \\
\hline Efisiensi isentropik turbin & 60 & $\%$ \\
\hline Efisiensi isentropik pompa & 60 & $\%$ \\
\hline Laju massa gas buang & 277.77 & $\mathrm{~kg} / \mathrm{s}$ \\
\hline
\end{tabular}

\section{HASIL DAN PEMBAHASAN}

Hasil perancangan dapat dilihat pada gambar 5,6, dan 7. Fluida kerja R142b memiliki efisiensi maksimum ketika sistem bekerja dengan tekanan evaporator sebesar 3.7 MPa dengan efisiensi sebesar $18.54 \%$. Hal ini dikarenakan ketika tekanan evaporator dinaikkan peningkatan kerja yang dihasilkan tidak terlalu besar sehingga menyebabkan efisiensi menurun. Sedangkan fluida kerja lain (isopentane dan R123) menunjukkan tren peningkatan efisiensi seiring dengan kenaikan tekanan evaporator. Namun terdapat batas untuk peningkatan tekanan evaporator yaitu dari temperatur pinch antara gas buang dengan fluida kerja. R123 menghasilkan efisiensi sebesar $18.51 \%$ dengan tekanan evaporator sebesar $1.12 \mathrm{Mpa}$. Isopentane menghasilkan efisiensi sebesar 17.84 dengan tekanan evaporator $1.02 \mathrm{Mpa}$.

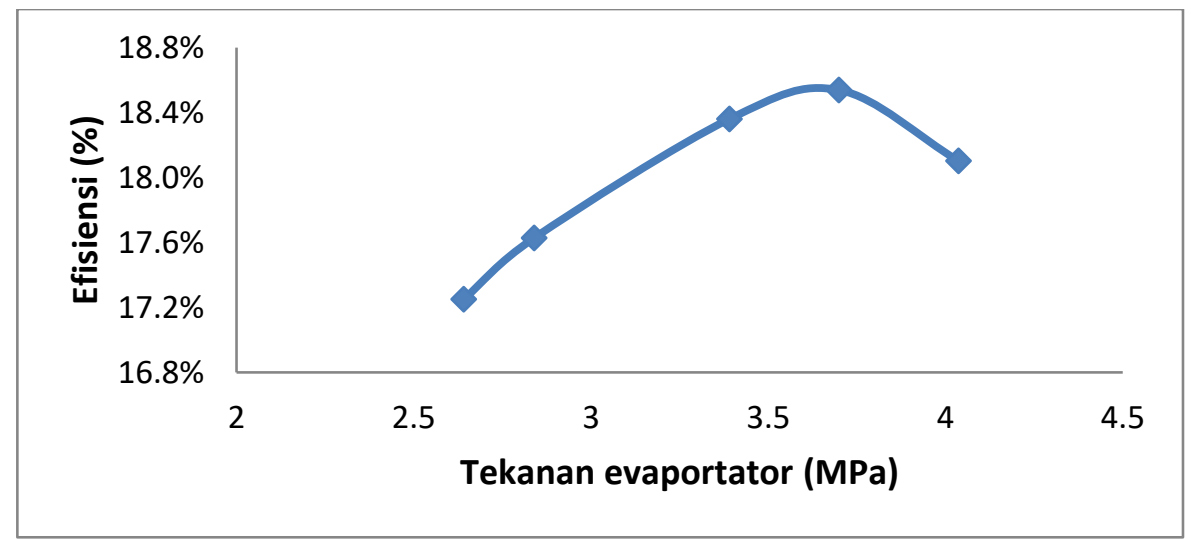

Gambar 5 kurva efisiensi sistem terhadap tekanan evaporator R142b

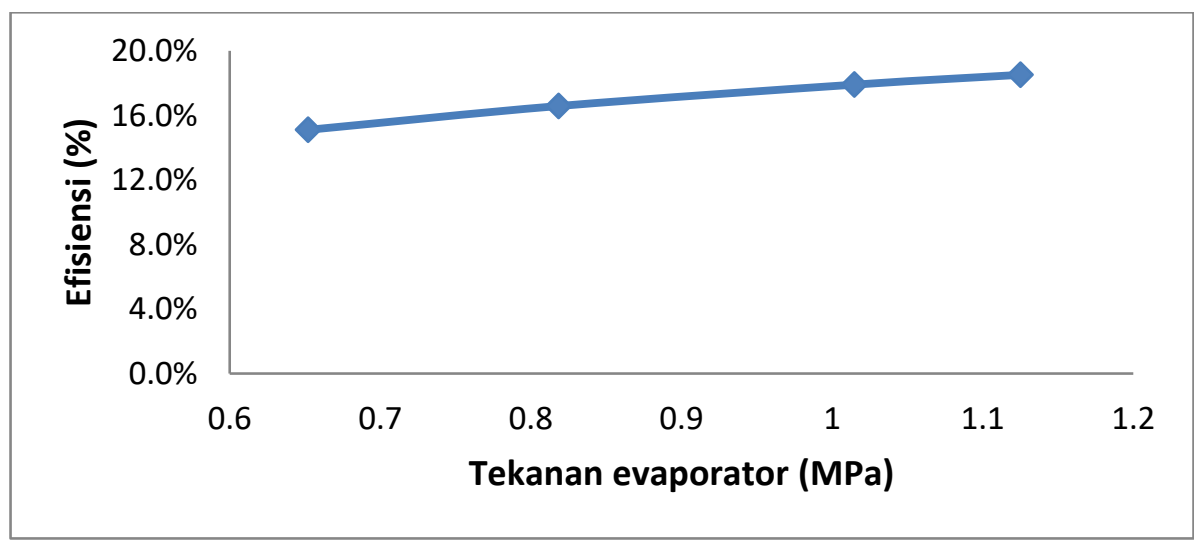

Gambar 6 kurva efisiensi sistem terhadap tekanan evaporator R123 


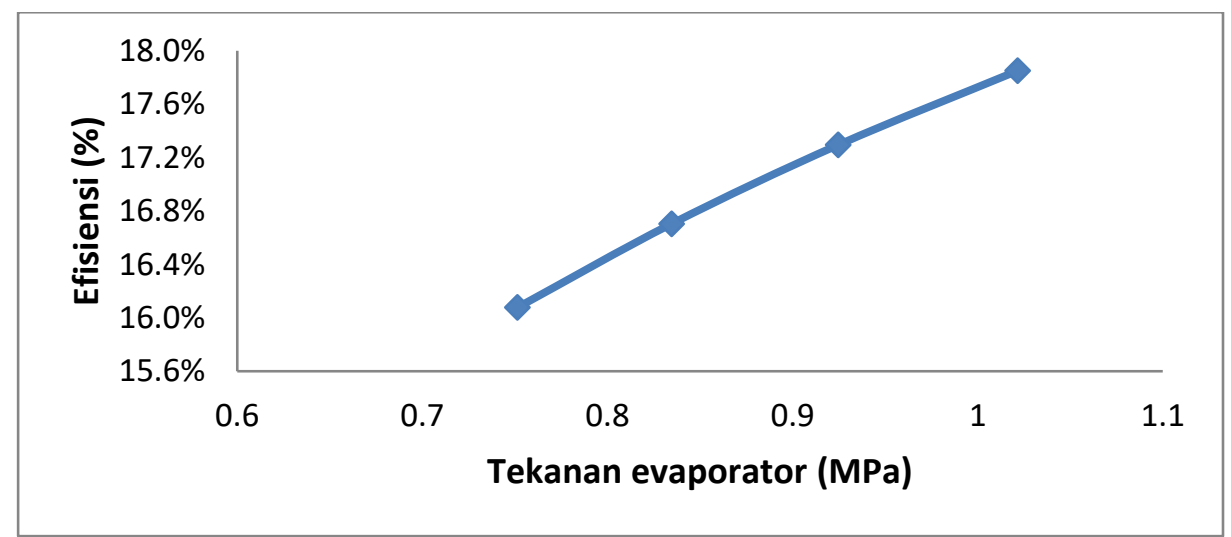

\section{Gambar 7 kurva efisiensi sistem terhadap tekanan evaporator Isopentane}

Gambar 8 menunjukkan grafik temperatur pinch antara fluida organik dan gas buang. Grafik ini menunjukkan proses perpindahan panas antara gas buang dan fluida kerja. Semakin kecil temperatur pinch maka akan semakin kecil rugi-rugi yang terjadi namun akan menghasilkan komponen penukar kalor yang besar. Semakin besar temperatur pinch maka akan semakin besar rugi-rugi akibat perbedaan temperatur yang cukup tinggi, namun komponen penukar kalor yang diperlukan akan semakin kecil. Pada perancangan temperatur pinch dibatasi sebesar $5^{\circ} \mathrm{C}$.

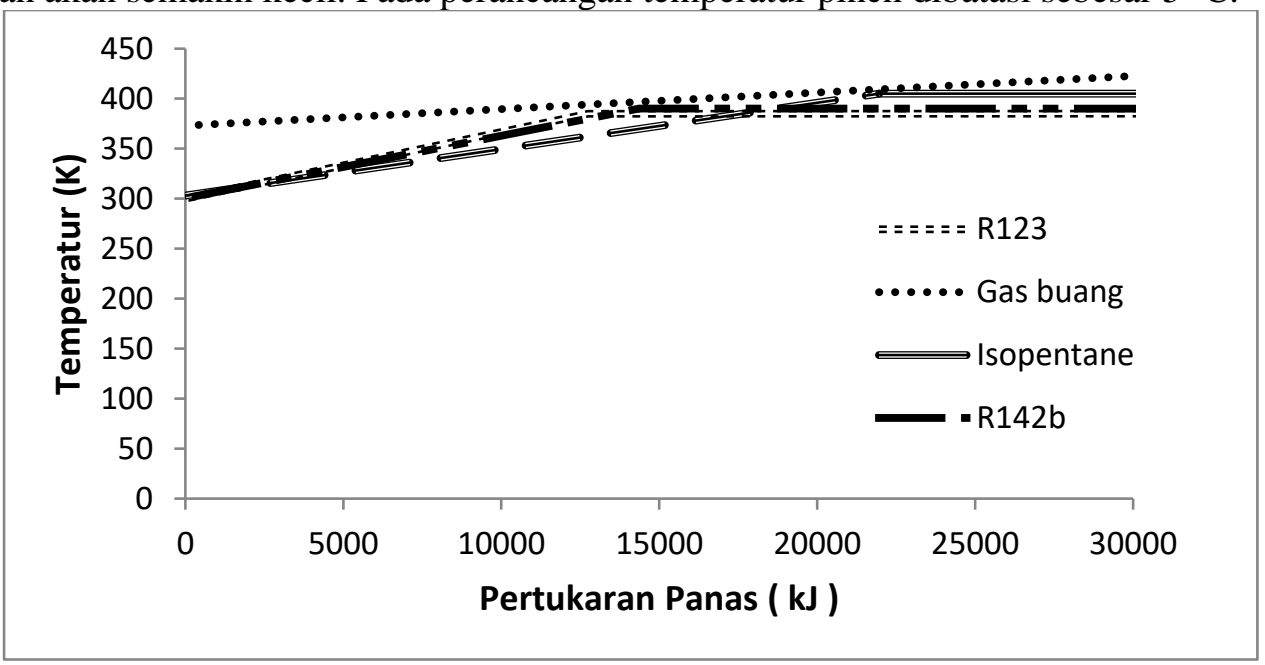

Gambar 8 Grafik temperatur pinch antara fluida organik dengan gas buang

Hasil perancangan untuk masing-masing fluida kerja ditunjukkan pada tabel 3.

Tabel 3 Parameter hasil perancangan

\begin{tabular}{|c|c|c|c|c|}
\hline Parameter & Satuan & R142b & $\mathbf{R 1 2 3}$ & Isopentane \\
\hline \hline Massa fluegas & $\mathrm{kg} / \mathrm{s}$ & 277.77 & 277.77 & 277.77 \\
\hline Massa fluida organik & $\mathrm{kg} / \mathrm{s}$ & 126.7 & 138.7 & 64.6 \\
\hline $\mathbf{W}_{\text {Turbin }}$ & $\mathrm{kW}$ & 6053 & 5705 & 5502 \\
\hline $\mathbf{W}_{\text {pompa }}$ & $\mathrm{kW}$ & 399 & 96 & 94 \\
\hline Q $_{\text {evaporator }}$ & $\mathrm{kW}$ & 30498 & 30296 & 30294.9 \\
\hline Q $_{\text {kondensor }}$ & $\mathrm{kW}$ & 24844 & 24687.4 & 24887.3 \\
\hline Efisiensi & $\%$ & 18.54 & 18.51 & 17.85 \\
\hline
\end{tabular}




\section{KESIMPULAN}

Siklus rankine organik pada PLTU dengan pemanfaatan panas dari gas buang yang memiliki temperatur sebesar $150^{\circ} \mathrm{C}$. Panas gas buang ini digunakan untuk menguapkan fluida kerja organik yang memiliki temperatur didih yang rendah. Hasil perancangan sistem siklus rankine organik mampu menghasilkan daya sebesar $6053 \mathrm{~kW}$ (R142b), $5705 \mathrm{~kW}$ (R123), dan 5502 (Isopentane) serta efisiensi sebesar $18.54 \%, 18.51 \%$, dan $17.85 \%$ untuk fluida kerja R142b, R123, dan Isopentane.

\section{DAFTAR PUSTAKA}

[1] R. Tucker, "Waste heat recovery system at Farleigh Hospital.," Hosp. Eng., vol. 33, no. 8, pp. 12-14, 1979.

[2] Ministry of Energy and Mineral Resources of Indonesia, "Rencana Usaha Penyediaan Tenaga Listrik PT. PLN (Persero) 2016-2025.” 2016.

[3] C. Wang et al., "Application of a low pressure economizer for waste heat recovery from the exhaust flue gas in a 600 MW power plant," Energy, vol. 48, no. 1, pp. 196-202, 2012.

[4] B. F. Tchanche, G. Lambrinos, A. Frangoudakis, and G. Papadakis, "Low-grade heat conversion into power using organic Rankine cycles - A review of various applications," Renew. Sustain. Energy Rev., vol. 15, no. 8, pp. 3963-3979, 2011.

[5] T. K. Zhelev and K. A. Semkov, "Cleaner flue gas and energy recovery through pinch analysis," J. Clean. Prod., vol. 12, no. 2, pp. 165-170, 2004.

[6] M. Khennich and N. Galanis, "Optimal design of ORC systems with a low-temperature heat source," Entropy, vol. 14, no. 2, pp. 370-389, 2012.

[7] J. Nouman, "Comparative studies and analyses of working fluids for Organic Rankine Cycles -ORC," 2012.

[8] S. Maalouf, E. Boulawz Ksayer, and D. Clodic, "Investigation of direct contact condensation for wet flue-gas waste heat recovery using Organic Rankine Cycle," Energy Convers. Manag., vol. 107, pp. 96-102, 2016. 